\title{
EXPERIMENTAL BEHAVIOR OF HIGH STRENGTH CONCRETE-FILLED SQUARE STEEL TUBE UNDER BI-AXIAL ECCENTRIC LOADING
}

\author{
GuoChang $\mathrm{Li}^{*}$, Zhijian Yang and Yan Lang \\ School of Civil Engineering, Shenyang Jianzhu University, Shenyang, China \\ *(Corresponding author: E-mail: cegcli@sjzu.edu.cn)
}

Received: 31 January 2010; Revised: 7 June 2010; Accepted: 25 June 2010

\begin{abstract}
An experimental investigation on the behaviour of square steel tube columns filled with high-strength concrete in this study was done. A total of six high strength concrete-filled square steel tube (HCFST) columns subjected to bi-axial eccentric loading were constructed and tested. The primary test parameters were the slenderness ratios (varied from 13.9 to 27.7 ), steel ratios(7\% and $13 \%$ ), and eccentricity along major axis was $71 \mathrm{~mm}$. The test results demonstrate the influence of these parameters on the strength and behavior of concrete-filled square steel tube columns. As what shows in the experiment, the steel ratio is an important factor which influences the bearing capacity of the specimens, and the stable bearing capacity of the specimens decreased rapidly with the increasing slenderness ratio. The specimens failed to work out of instability. Proper material constitutive models for HCFST columns are applied and verified by the nonlinear finite element software ABAQUS against experimental data. A comparison of experimental failure loads with the predicted failure loads in accordance with the method described in the reference showed good agreement.
\end{abstract}

Keywords: Square steel tube, High strength concrete, Bi-axial eccentric loading, Finite element analysis, Slenderness ratio, Steel ratio

\section{INTRODUCTION}

Concrete-filled steel tube columns have recently undergone increased usage throughout the world, which has been influenced by the development of high-strength concrete. With the ever-increasing application of high-strength concrete in civil engineering, the research on steel tube filled with high-performance concrete columns is imperative nowadays. Concrete-filled square steel tube (CFST) column has a high bearing capacity, good plasticity, toughness, fatigue resistance and other superior mechanical properties, but it also has unique characteristics, (1) simple form of beam-to-column connection, (2) flexible building layout, (3) good stability behavior with large cross-section moment of inertia, (4) convenient construction (Han [1], Shosuke [2]). Thus, in recent years CFST columns have been widely applied in practical project, such as, the cross-section of $1400 \mathrm{~mm} \times 1400 \mathrm{~mm}$ concrete filled square steel tube columns were used in Wuhan International Stock Exchange Building with 68 stories and a height of $243 \mathrm{~m}$.

When subjected to the load of horizontal wind or earthquake, frame columns of high-rise building structures usually tend to be bi- axial bending, especially the corner columns of the structures. It is very important to describe the behavior of such columns for rational analysis and design, but most of studies on CFST at home or abroad mainly focused on axial compression and uniaxial eccentric compression(Toshiaki [3], Han [4], Campione [5]). Some theoretical and experimental studies have been conducted for the determination of the behavior of eccentrically loaded CFST columns (Zegbicbe [6]). Mursi and Uy have presented experimental and theoretical studies of fabricated high strength steel columns subjected to biaxial bending (Mursi [7], Uy [8]). Serkan Tokgoz constructed a experimental investigation on the structural behavior of steel tubular columns in-filled plan and steel reinforced concrete subjected biaxial bending and axial load (Serkan and Cengiz [9]). Su-Mei Zhang has done a lot of research on concrete-filled rectangular hollow section (RHS) steel tubes subjected to axial compression combined with bi- axial bending, and achieved a few success (Guo [10]). Bridge, R studied on four concrete-filled rectangular hollow section(RHS) 
steel tubes subjected to bi-axial eccentric loading, and showed that the bearing capacity of the specimen has a close relationship with the eccentric angle (Bridge [11]). Shakir-Khalil H conducted a test of nine concrete-filled rectangular hollow section(RHS) steel tube columns subjected to bi-axial eccentric loading, with a eccentric angle of $45^{\circ}$ and concrete strength of $94.1 \mathrm{MPa}$ (Shakir-Khalil [12]).

The main objective of this study is to investigate the behavior and strength of high strength concrete-filled square steel tube (HCFST) columns. For this purpose, several HCFST columns were constructed and tested subjected to bi-axial eccentric loading. The test results of HCFST column specimens have been compared with the analysis results and discussed in this paper.

\section{EXPERIMENTAL INVESTIGATION}

\subsection{Specimens and Parameters}

A total of six CFST column specimens were constructed with high-strength concrete. The cross-section of the specimen was $200 \mathrm{~mm} \times 200 \mathrm{~mm}$ with a wall thickness of $4 \mathrm{~mm}$ or $6 \mathrm{~mm}$. The length of the columns varied from $800 \mathrm{~mm}$ to $1600 \mathrm{~mm}$ in increments of $400 \mathrm{~mm}$ and the steel tube was cold-formed Q235 square tube. The eccentricity along major axis was $71 \mathrm{~mm}$, and eccentric angle was $45^{\circ}$. The primary test parameters were slenderness ratios and steel ratios, Table 1 gives the details of the specimens.

Ready-mixed concrete with a designed strength of C60 was used in the test. Three $150 \mathrm{~mm}$ cubes were cast and cured in conditions similar to the related specimens. The 28 day cube strength $\left(f_{c u}\right)$ was $65 \mathrm{MPa}$ and slightly increased on the column test day that was $79.7 \mathrm{MPa}$ (shown as in the Table 1). The modulus of elasticity $\left(E_{c}\right)$ of concrete was $3.81 \times 10^{4}$. Where $B$ is cross section height of steel tube, $t$ is nominal thickness of steel tube; $t$ 'is measured thickness of steel tube. $f_{y}$ is yield strength of steel; $f_{u}$ is ultimate tensile strength of steel; $E_{s}$ is elasticity modulus of steel.

Table1. Specimens in Details

\begin{tabular}{|c|c|c|c|c|c|c|c|}
\hline $\begin{array}{c}\text { Specimen } \\
\text { Number }\end{array}$ & $\begin{array}{c}B \\
(\mathrm{~mm})\end{array}$ & $\begin{array}{c}L \\
(\mathrm{~mm})\end{array}$ & $\begin{array}{c}t \\
(\mathrm{~mm})\end{array}$ & $\begin{array}{c}t^{\prime} \\
(\mathrm{mm})\end{array}$ & $\begin{array}{c}f_{y} \\
(\mathrm{MPa})\end{array}$ & $\begin{array}{c}f_{u} \\
(\mathrm{MPa})\end{array}$ & $\begin{array}{c}E_{s} \\
(\mathrm{Gpa})\end{array}$ \\
\hline ES4-4-71 & 200 & 800 & 4 & 3.5 & 306 & 430 & 200 \\
\hline ES4-6-71 & 200 & 800 & 6 & 5.8 & 340 & 440 & 206 \\
\hline ES6-4-71 & 200 & 1200 & 4 & 3.5 & 306 & 430 & 200 \\
\hline ES6-6-71 & 200 & 1200 & 6 & 5.8 & 340 & 440 & 206 \\
\hline ES8-4-71 & 200 & 1600 & 4 & 3.5 & 306 & 430 & 200 \\
\hline ES8-6-71 & 200 & 1600 & 6 & 5.8 & 340 & 440 & 206 \\
\hline
\end{tabular}

To determine the steel properties, three specimens were cut from randomly selected steel sheet. The specimens were tested in tension. From these tests, the average yield strength $\left(f_{y}\right)$, ultimate tensile strength $\left(f_{u}\right)$ as well as Young's modulus of elasticity $\left(E_{s}\right)$ were got. They are shown in Table 1 .

First of all, the bearing plate was welded at the bottom end of each CFST column specimen. Then, the concrete was casted into steel tubes. Progress vibration was employed in order to eliminate air pockets in the concrete and give a homogeneous mix. The CFST specimens were left with top open to the air for two weeks for the concrete to set. Prior to testing, the top surfaces of the concrete-filled steel tubes were ground smooth and flat using a grinding wheel with diamond cutters to ensure that the load was able to be applied evenly across the cross-section and simultaneously to the steel and concrete. Finally, the base plate was welded at the top end of each CFST specimen. 


\section{$2.2 \quad$ Testing Equipment}

All of the columns were carried out on a $5000 \mathrm{kN}$ capacity loading jack in the Structural Engineering Laboratory of Shenyang Jianzhu University. Knife edges were used on either end to ensure that pinned ends were achieved in all the experiments conducted. The test setup is illustrated in Figure 1 and Figure 3. A number of linear varying displacement transducers (LVDT's) were used to measure the out-of-plane deflections of the column at the mid-height and quarter points of the column (two for short column, six for long column ), and two LVDT's were set up at the bottom to observe the total vertical deformation of the specimen.

Strain gauges were used to measure the surface strains of the steel tube at the mid-height section at various locations. Each column was instrumented with twenty-two strain gauges. Figure 2 shows the strain gauge location and numbering scheme for the columns. The transducers were calibrated before they were used in the test. The U-CAM 70A static data acquisition system was arranged to collect the load, the lateral deflections, and the strain measurements.

\section{$2.3 \quad$ Testing Method}

At each load increment, the strain readings and the deflection measurements were recorded. Special attention was given to verifying the correct position of the column before loading. The load was applied in small increment. Each load interval was maintained for 1 minute. Each of the first few increments of load was about $10 \%$ of the predicted failure load. For the first increment, a complete check of displacement, strains and load was carried out. Several loading and unloading cycles were performed at this stage. When the results were satisfactory, began to load in increments of $10 \%$ estimated ultimate load each step. After steel tube yielded, each step was about 1/15 of estimated ultimate load. Every load lasts about $2 \sim 3$ min. Slow and continuous load was applied when the specimen approaches to destroy.

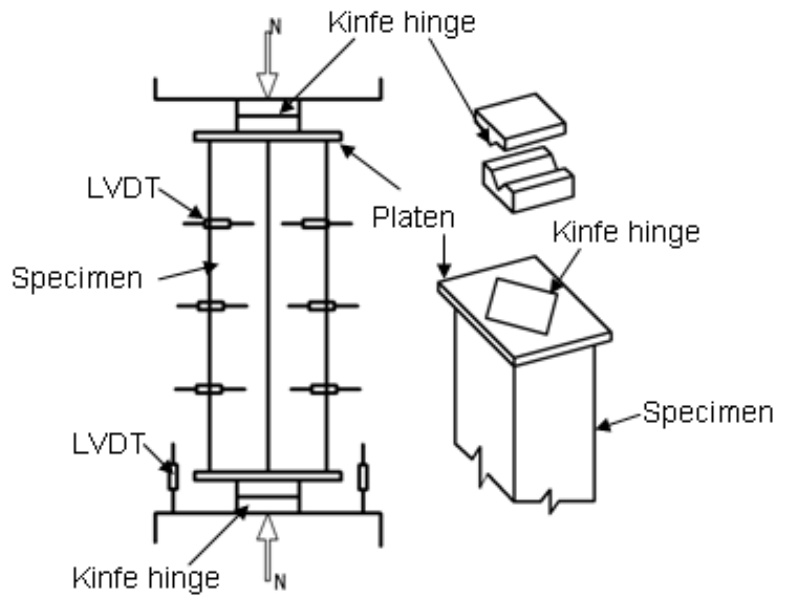

Figure 1. Experimental Equipment

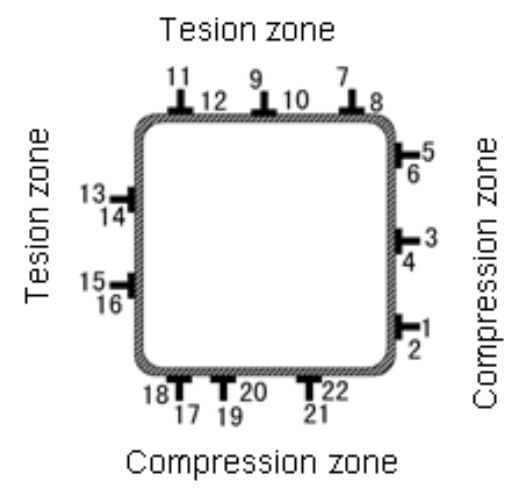

Figure 2. The Location of Strain Gauges

\subsection{Testing Phenomenon and Analysis}

It was observed in the experimental study that the column specimens tested mostly illustrate overall buckling or global instability and behaved in a ductile manner. The load carrying capacity of the columns decreased when reached the failure load. It was concluded from the test that the slenderness and steel ratio had significantly effect on the ultimate strength capacity of HCFST columns subjected to bi-axial eccentric loading. The typical failure mode of a HCFST column is illustrated in Figure 4. 


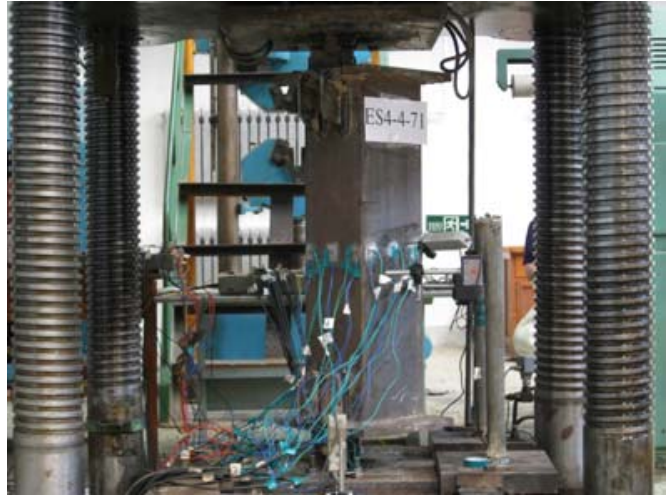

Figure 3. The Typical CFST Column Specimen before Testing

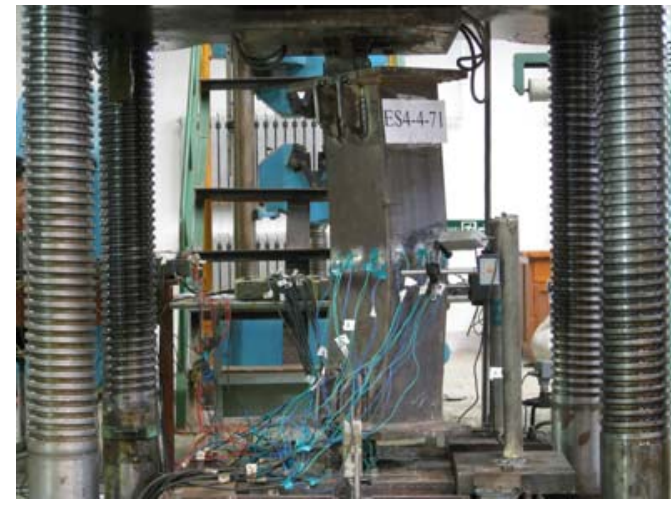

Figure 4. The Typical CFST Column Specimen after Testing

Figure 5(a) shows the specimen after failure. All column specimens failed at the mid-height by rupture of the steel casing in the tension zone and buckling of steel in the compression zone at the termination of loading. Typical failure mode was overall buckling failure. The removal of steel from the failed columns revealed crushing and cracking of concrete in the compression and tension zones, respectively, at mid-length sections, which is illustrated in Figure. 5(b) and Figure. 5(c).

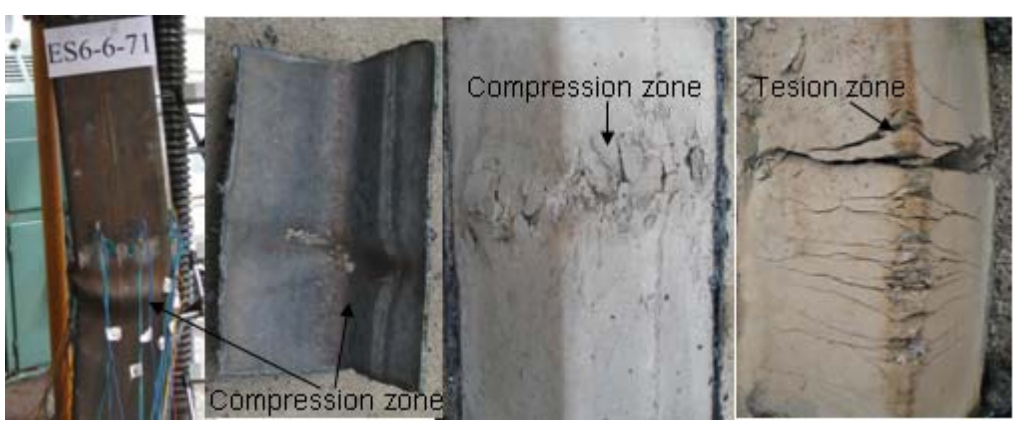

(a)

(b)

(c)

Figure 5. Specimen after Failure

The load $(N)$ versus axial strain $(\varepsilon)$ curves for the columns are presented in Figure 6 . which is the maximum absolute value of strains in the compression and tension zones. The strain value measured on the compression side of the CFST column was about 0.003 , which indicated that the steel tube yielded before the critical load was reached.

Figure 7 is the deflection curves of two typical column specimens measured in the process of load, which is compared to ideal half-sine-wave. The vertical coordinate is height $(H)$ of position on the column. The abscissa is the deflection $\left(u_{\mathrm{m}}\right)$ of different position in the process of loading. $n$ is the ratio of real-time load $(N)$ to ultimate bearing capacity $\left(N_{u}\right)$, and the dashed line is half-sine-wave in Figure 7 . The deflection $u_{\mathrm{m}}$ was calculated by the deflection of two tension face $\left(u_{m}=\sqrt{u_{x}^{2}+u_{y}^{2}}\right)$. From the deformation observed in the test and the test dates gained, the values of $u_{\mathrm{x}}$ and $u_{\mathrm{y}}$ are very close. The deflection curves of test and the ideal half-sine-wave curves fit well, and the smaller of the load, the better the curves fit. 


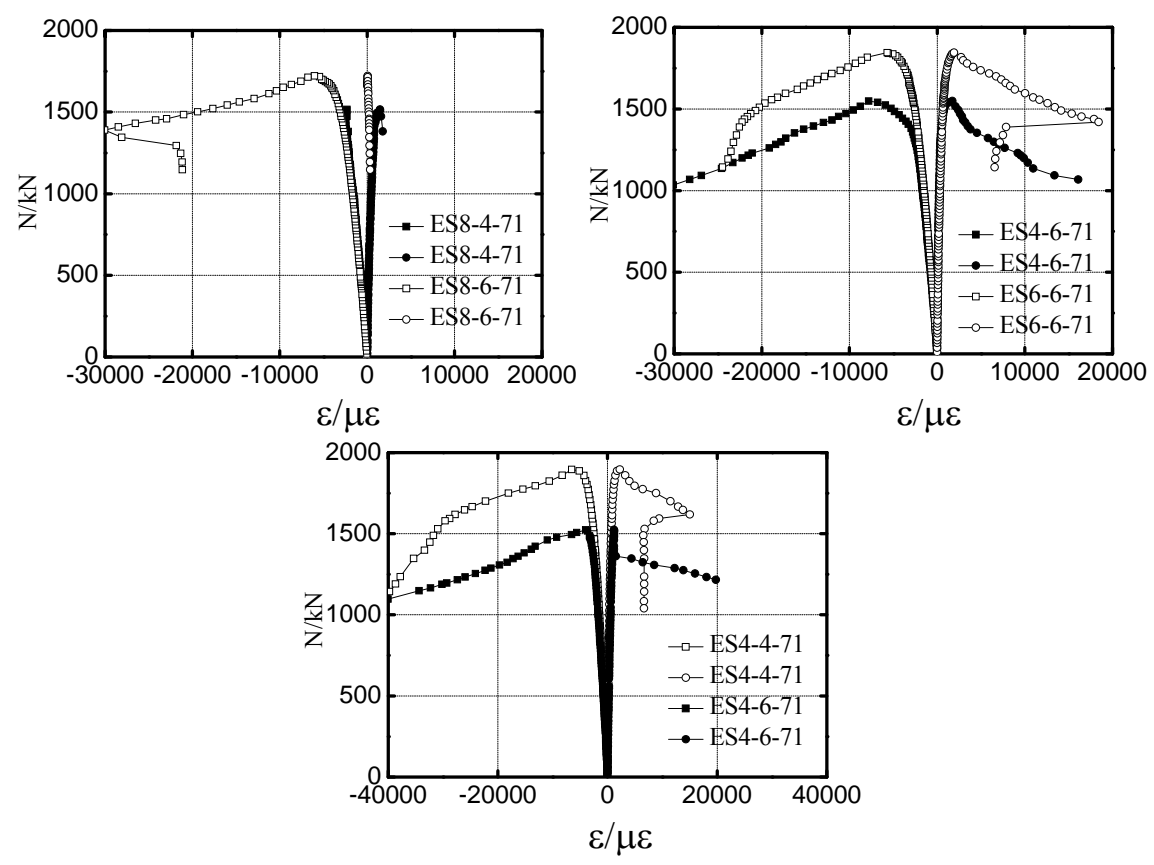

Figure 6. Load $(\mathrm{N})$ Versus Axial Strain $(\varepsilon)$ Relations

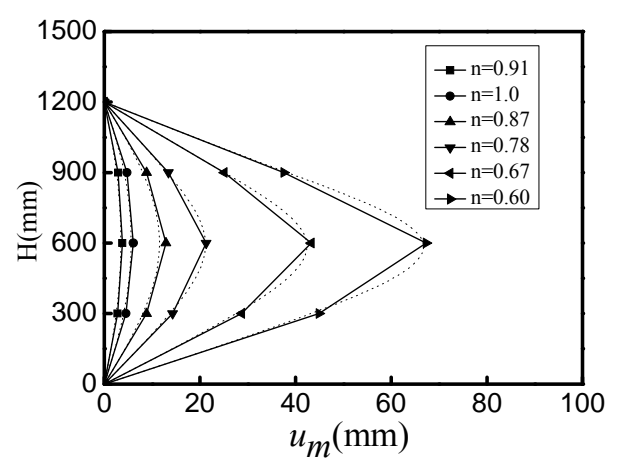

(a) ES6-6-71

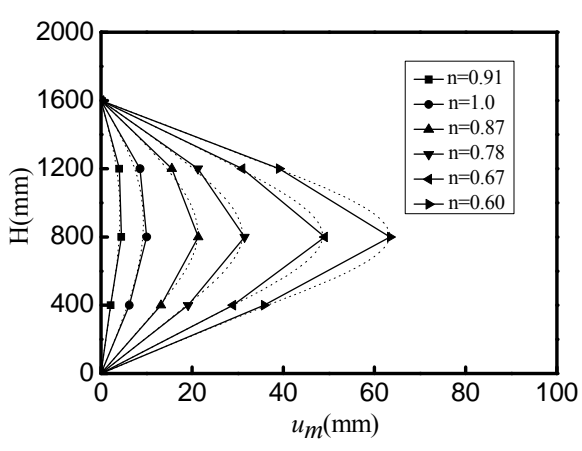

(b) ES8-6-71

Figure 7. The Deflections Curves of Specimen

When the load was small, the lateral deflection at middle height was small and approximately proportional to the applied load. However, when load reached about $70 \%$ of the ultimate load, the deflection of the mid-span increased significantly. As the deflection reached a certain value, the bearing capacity began to descend slowly, and the deflection increased quickly.

Figure 8 is the cross-sectional longitudinal strains distribution of column specimens. In order to check plane-section assumption, the strain values on $\mathrm{x}$ and $\mathrm{y}$-axis are projected to the diagonal axis. Figures 8 shows that the strains of specimen can be connected to a straight line from the beginning to the ultimate bearing capacity under different level loading and the strain distribution of cross section is consistent with plane-section assumption. 


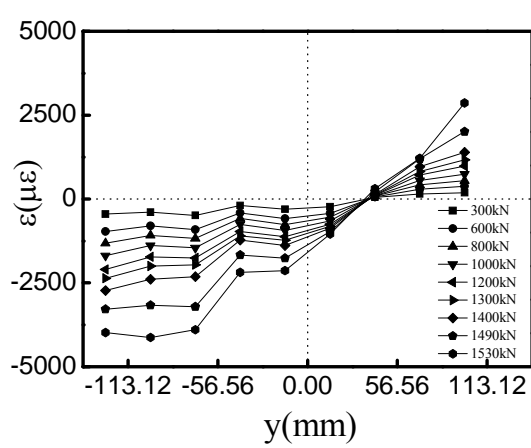

(a) ES4-4-71

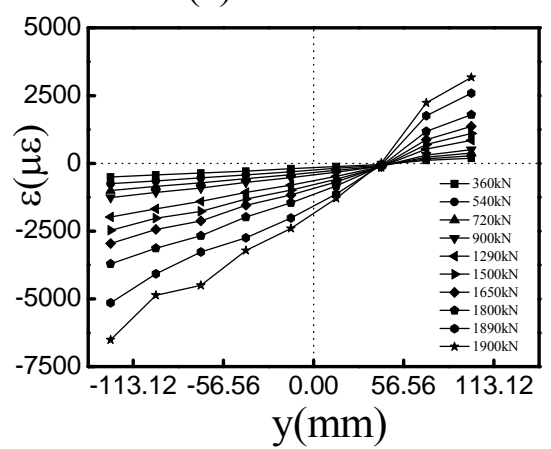

(d) ES4-6-71

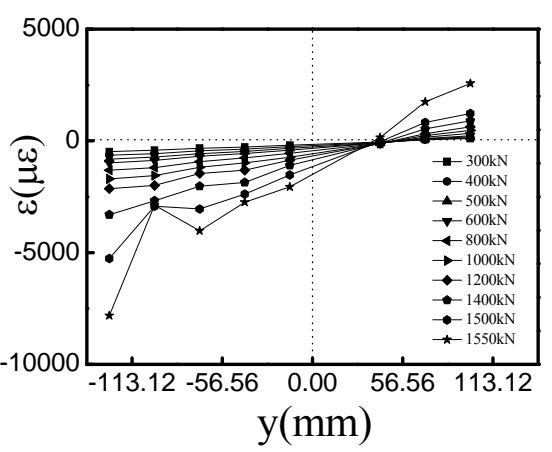

(b) ES6-4-71

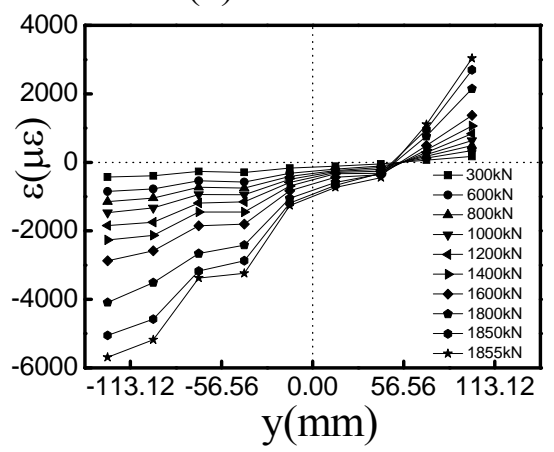

(e) ES6-6-71

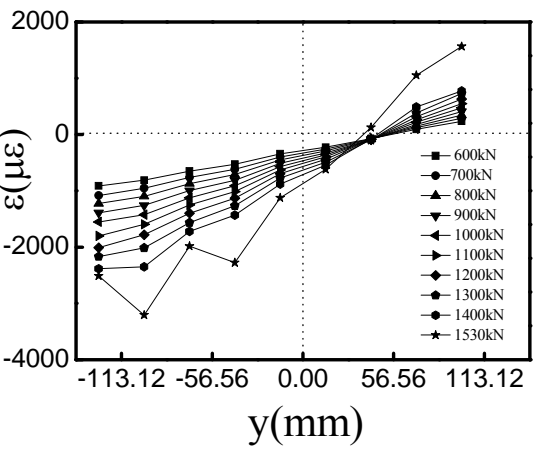

(c) ES8-4-71

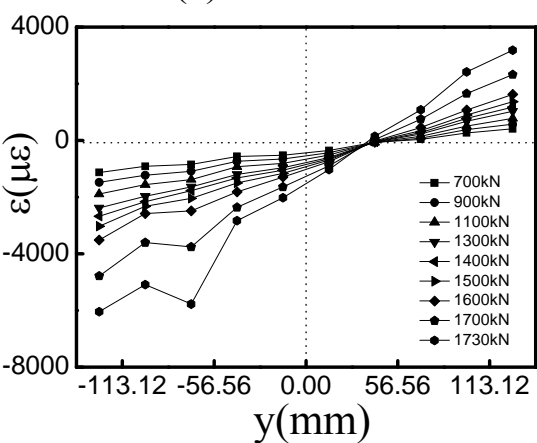

(f) ES8-6-71

Figure 8. Plane-Section Assumption

\section{FINITE ELEMENT ANALYSIS}

\subsection{Material Properties and Constitutive Models}

The nonlinear finite element program ABAQUS (Al-Rodan A [13], Hsuan-Teh $\mathrm{Hu}$ [14,15]) was employed to perform numerical stimulations of HCFST columns subjected to bi-axial eccentric loading. To achieve this goal, proper material constitutive models for steel tube and concrete were proposed.

In the analysis, the Poisson's ration $v$ and the elastic modulus $E_{s}$ of the steel tube are assumed to be $v=0.3$ and $E_{S}=206 \mathrm{Gpa}$. The constitutive relationship of steel adopts elastic-plastic constitutive model provided by ABAQUS to meet Von Mises yield criterion, and Isotropic strengthening rule. The steel's stress-strain relationship was shown by entering corresponding steel stress and strain point. As cold-formed steel tube was used in the test and the steel stress-strain relationship referred to four-line model suggested by Abdel-Rahman and Sivakumaran, in this analysis, the material was divided into corner area and flat area (Abdel-Rabman N [16]). The stress-strain curve is described with the following equations:

$$
\sigma= \begin{cases}E_{\mathrm{s}} \varepsilon & \left(\varepsilon \leq \varepsilon_{e}\right) \\ f_{\mathrm{p}}+E_{\mathrm{s} 1}\left(\varepsilon-\varepsilon_{e}\right) & \left(\varepsilon_{e}<\varepsilon \leq \varepsilon_{e 1}\right) \\ f_{\mathrm{ym}}+E_{\mathrm{s} 2}\left(\varepsilon-\varepsilon_{\mathrm{e} 1}\right) & \left(\varepsilon_{e 1}<\varepsilon \leq \varepsilon_{e 2}\right) \\ f_{\mathrm{y}}+E_{\mathrm{s} 3}\left(\varepsilon-\varepsilon_{\mathrm{e} 2}\right) & \left(\varepsilon_{e 2}<\varepsilon\right)\end{cases}
$$

Where $f_{y}$ is the yield strength of flat area; $E_{\mathrm{s}}$ is Young's modulus of elasticity, $E_{\mathrm{s} 1}, E_{\mathrm{s} 2}, E_{\mathrm{s} 3}$ is Slope of line, $E_{\mathrm{s} 1}=0.5 E_{\mathrm{s},} E_{\mathrm{s} 2}=0.1 E_{\mathrm{s}}, E_{\mathrm{s} 3}=0.05 E_{\mathrm{s}} ; f_{p}, f_{m}$ is stress of feature point $f_{p}=0.75 f_{y}, f_{p}=0.875 f_{y}$; $\varepsilon_{\mathrm{e}}, \varepsilon_{\mathrm{e} 1}, \varepsilon_{\mathrm{e} 2}$ is strain of feature point $\varepsilon_{\mathrm{e}}=0.75 f_{\mathrm{y}} / E_{\mathrm{s}}, \varepsilon_{\mathrm{e} 1}=\varepsilon_{\mathrm{e}}+0.125 f_{\mathrm{y}} / E_{s 1}, \varepsilon_{\mathrm{e} 2}=\varepsilon_{\mathrm{e} 1}+0.125 f_{\mathrm{y}} / E_{\mathrm{s} 2}$; The yield strength of flat area $f_{y}$ was given with the following expression: 
$f_{y c}=\left[0.6 b(r / t)^{\mathrm{m}}+0.4\right] f_{\mathrm{y}}$

Where $b=3.69\left(f_{\mathrm{u}} / f_{\mathrm{y}}\right)-0.819\left(f_{\mathrm{u}} / f_{\mathrm{y}}\right)^{2}-1.79$, and $m=0.192\left(f_{\mathrm{u}} / f_{\mathrm{y}}\right)-0.068, f_{u}$ is ultimate tensile strength of steel.

Concrete used a plastic damage model provided by ABAQUS, and the model can simulate the plastic behavior of concrete well. The Poisson's ration of concrete was assumed to be $v=0.2$. When concrete is subjected to laterally confining pressure, the concrete compressive strength and the corresponding strain are much higher than those of unconfined concrete. And the softening phenomenon and ductility has also been improved compared with the case of uniaxial compression. Thus, it is difficult to simulate core concrete that is passive constrained by steel tube through entering ordinary uniaxial compression stress-strain model. Considering the confinement factor $\zeta$ and concrete strength $f_{c}$, the stress-strain relationship of the core concrete proposed by Liu Wei is applied to ABAQUS finite element analysis ( Han, L.H [1]).

In this study, fracture energy-crack displacement model was used to express tension stress-strain of concrete, which is calculated as following [17]:

$G_{f}=a \cdot\left(\frac{f_{\mathrm{c}}}{10}\right)^{0.7} \times 10^{-3}(\mathrm{~N} / \mathrm{mm})$

Where $G_{f}$ is fracture energy; coefficient $a=1.25 d_{\max }+10, d_{\max }$ is the maximum particle diameter of coarse aggregate; $f_{c}$ is mean compressive strength of concrete.

\section{2 $\quad$ Finite Element Model}

Element types of steel tube and concrete were C3D8R (an 8-node linear brick, reduced integration, hourglass control). Mapping mesh was used to mesh the element. The contact between the concrete and the steel was modeled with hard contact at normal direction and Coulomb friction at tangential direction. Coulomb friction model was used to simulate the steel tube and the mezzanine section of concrete shear force transfer. The friction coefficient used in all the analyses is 0.3 .

Due symmetry, only one fourth of the HCFST column was analyzed (Figure 9). Symmetric boundary conditions were enforced on the symmetric planes which were XSYMM and ZSYMM boundary conditions. The plate of the column was allowed to rotate at $x$-axis, and displacement was allowed to take place in the $\mathrm{z}$ direction. The analysis load was applied by displacement control, and incremental iterative method was used to solve nonlinear equations.

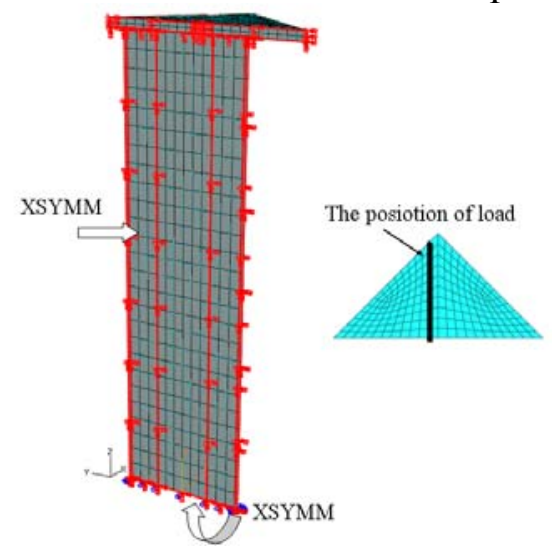

Figure 9. Boundary Condition of Analytical Model 


\subsection{Numerical Simulation}

The results of numerical simulations of HCFST are given in the Table 2 and curves of load versus lateral deflection of mid-height for these columns are plotted against the experimental data in Figures 10. The numerical results show good agreement with the experimental data.

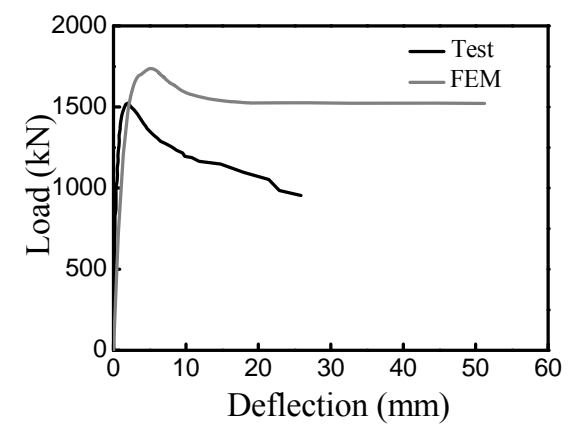

(a) ES4-4-71

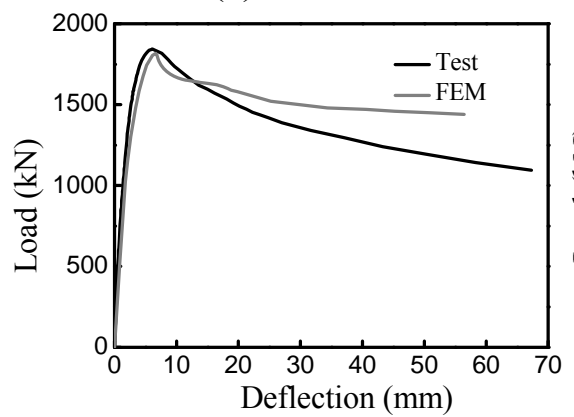

(d) ES6-6-71

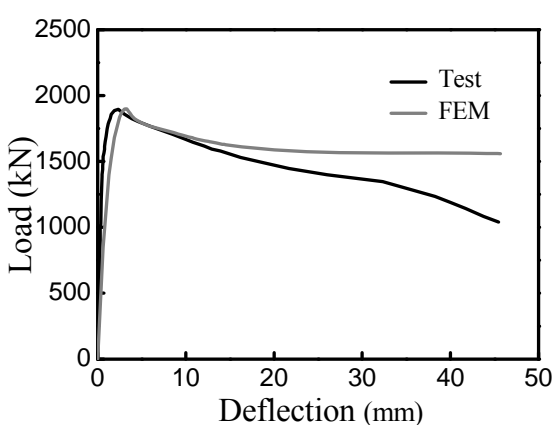

(b) ES4-6-71

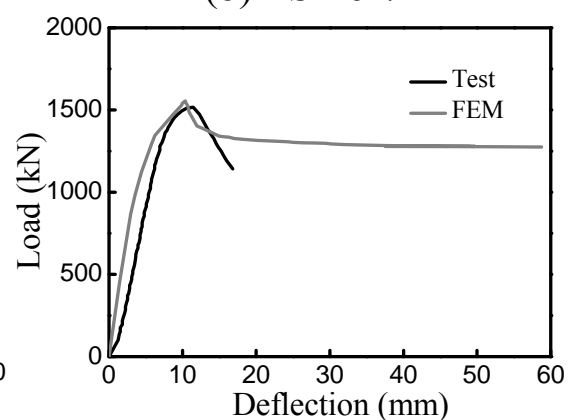

(e) ES8-4-71

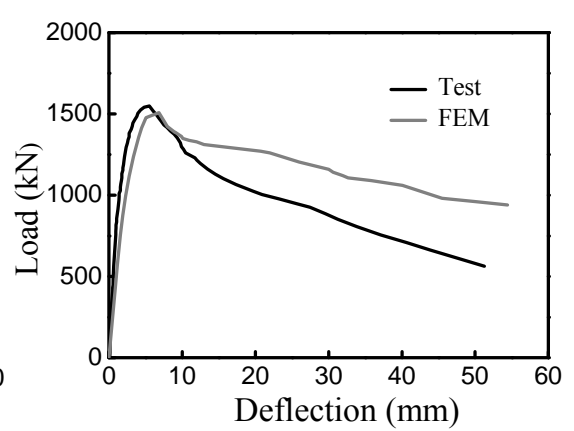

(c) ES6-4-71

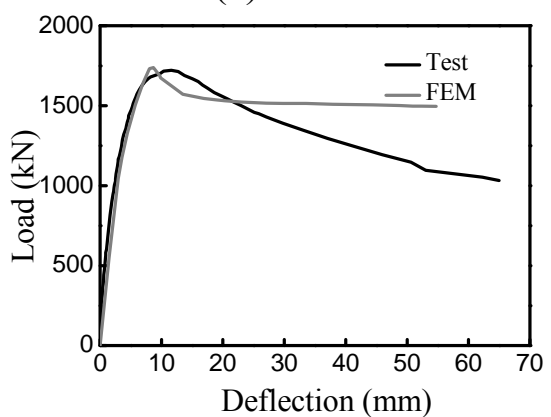

(f) ES8-6-71

Figure 10. Comparisons of Predicted Load Versus Deflection Curves of Columns with Tested Results

The concrete stress isoline of mid-height section, the longitudinal stress distribution in the core concrete section of column along the length of specimen EF6-6-71 is illustrated in Figures 11. The picture of $\mathrm{A}, \mathrm{B}$ and $\mathrm{C}$ are stress contour plots respectively corresponding to the load which is $0.75 N_{c l}$ (the ultimate bearing capacity of finite element calculation), $1.0 N_{c l}$ and $0.85 N_{c l}$. As what can be seen from Figures 11, the tension area expends and compression area reduced with the increasing of load, and the neutral axis gradually approaches to compression zone.

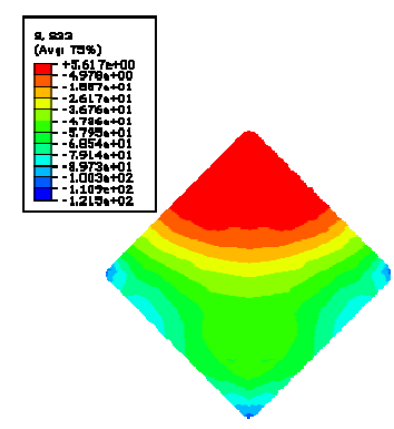

(a) A

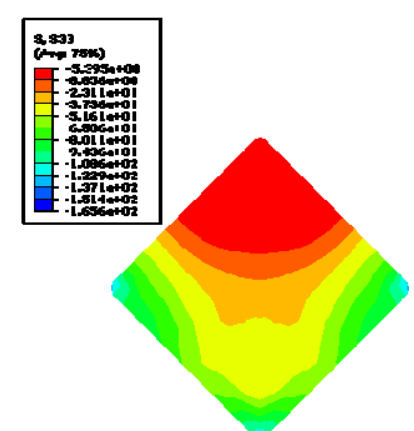

(b) B

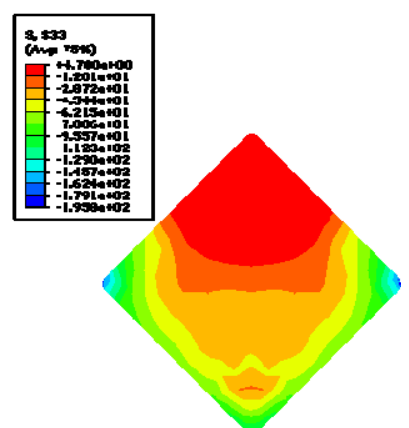

(c) $\mathrm{C}$

The Longitudinal Stress Distribution in the Core Concrete Section 


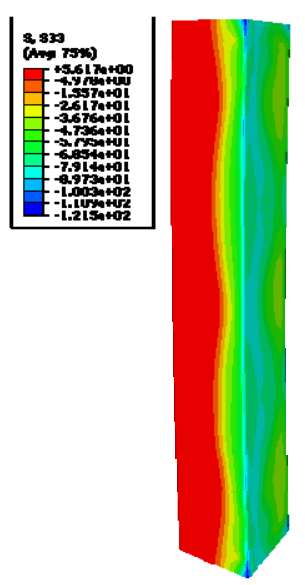

(d) A

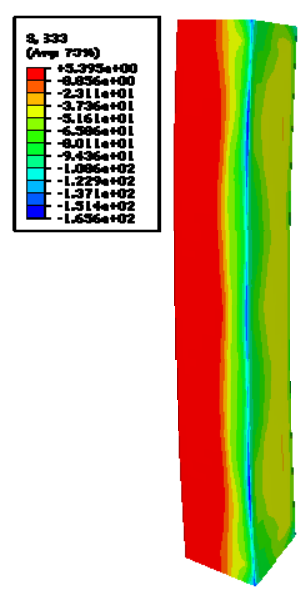

(e) B

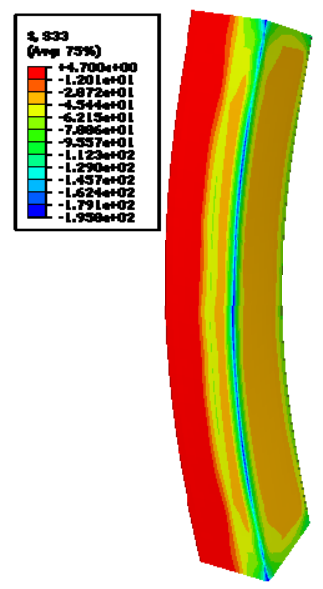

(f) $\mathrm{C}$

Figure 12. The Longitudinal Stress Distribution in the Core Concrete Section of Column along the Length

The concrete stress isoline of mid-height section is illustrated in Figures 12. The tension stress of concrete decreases from $0.0708 f^{\prime}{ }_{c}$ (Figure 12A) to $0.0583 f^{\prime}{ }_{c}$ (Figure 12C) with the increasing of the deflection. In addition, what the confined stress of compression zone corner increases constantly shows that corner confining effect is obvious.

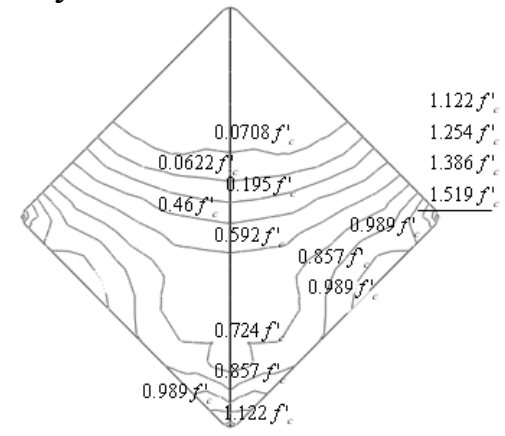

A

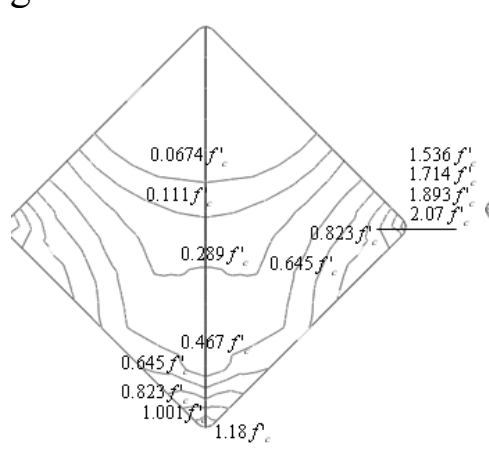

B

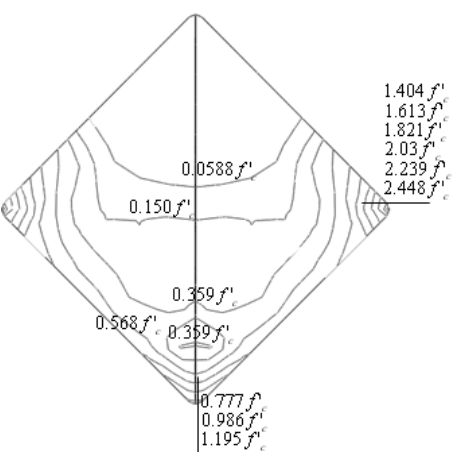

$\mathrm{C}$

Figure 12. The Longitudinal Stress Isoline in the Core Concrete Section

Figures 13 is the longitudinal stress distribution of steel tube along the length of specimen ES6-6-71. What the corner area of steel tube yielded earlier than flat area, shows that the confining effect of corner area is obvious. When the specimen reached ultimate bearing capacity the mid-length began to yield, from the mid-length to the ends.

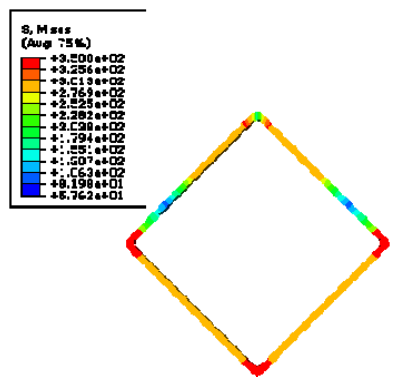

(a) A

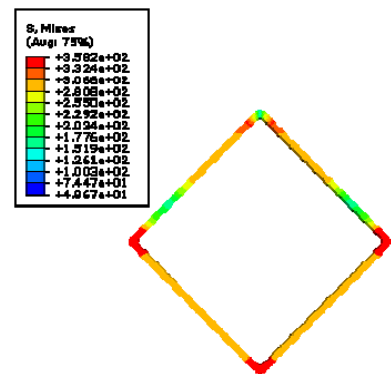

(b) B

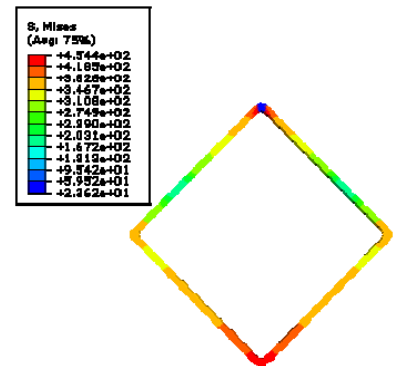

(c) $\mathrm{C}$

The Longitudinal Mises Stress Distribution of Mid-Height Section 


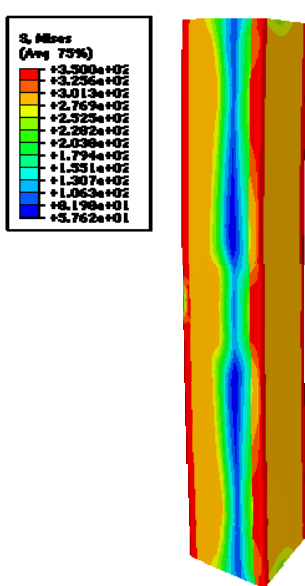

(d) A

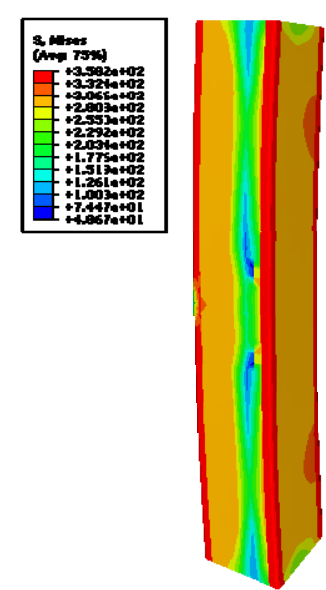

(e) B

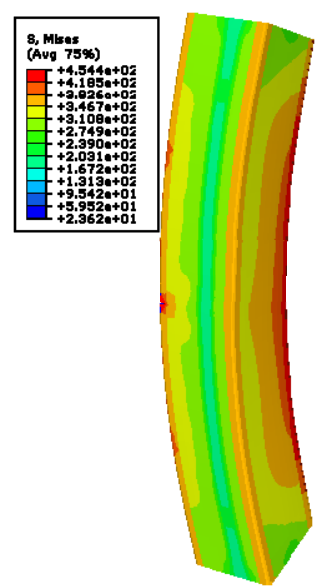

(f) $\mathrm{C}$

Figure 13. The Longitudinal Stress Distribution of Steel Tube along the Length

Figure 14 shows the ultimate bearing capacity of finite element calculation $\left(N_{c 1}\right)$ and measured values $\left(N_{e}\right)$. The ratio of $N_{c 1} / N_{e}$ is listed in Table 2 . The average is 1.005 and standard deviation is 0.038 . It can be seen that the calculation results agree well with the test data.

Table 2. Comparison of Test Results and Calculation Results

\begin{tabular}{|c|c|c|c|c|c|c|c|c|}
\hline $\begin{array}{c}\text { Specimen } \\
\text { number }\end{array}$ & $\begin{array}{c}t^{\prime} \\
(\mathrm{mm})\end{array}$ & $\begin{array}{c}f_{y} \\
(\mathrm{MPa})\end{array}$ & $\varphi_{x y}$ & $\begin{array}{c}N_{e} \\
(\mathrm{kN})\end{array}$ & $\begin{array}{c}N_{c 1} \\
(\mathrm{kN})\end{array}$ & $\begin{array}{c}N_{c 2} \\
(\mathrm{kN})\end{array}$ & $N_{c 1} / N_{e}$ & $N_{c 2} / N_{e}$ \\
\hline ES4-4-71 & 3.5 & 306 & 0.957 & 1524 & 1636.9 & 1501.2 & 1.074 & 0.985 \\
\hline ES4-6-71 & 5.8 & 340 & 0.958 & 1895.6 & 1899.4 & 1827.7 & 1.002 & 0.964 \\
\hline ES6-4-71 & 3.5 & 306 & 0.909 & 1548.4 & 1546.3 & 1406.1 & 0.999 & 0.908 \\
\hline ES6-6-71 & 5.8 & 340 & 0.913 & 1844.9 & 1818.2 & 1722.7 & 0.986 & 0.934 \\
\hline ES8-4-71 & 3.5 & 306 & 0.863 & 1516.5 & 1455.4 & 1314.4 & 0.96 & 0.867 \\
\hline ES8-6-71 & 5.8 & 340 & 0.869 & 1717.3 & 1738.4 & 1619.2 & 1.012 & 0.943 \\
\hline
\end{tabular}

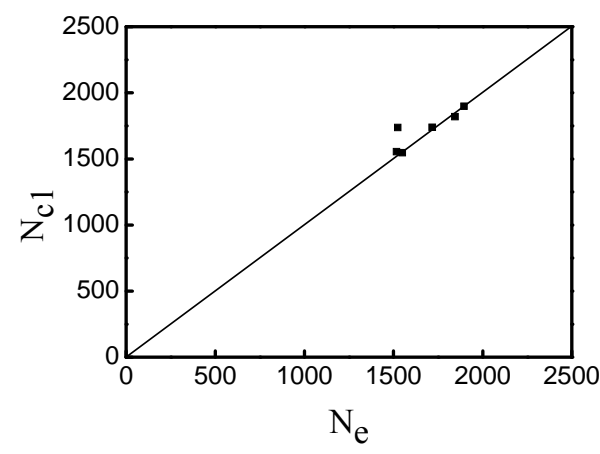

Figure 14. Comparisons of Finite Element Results Versus Test Results

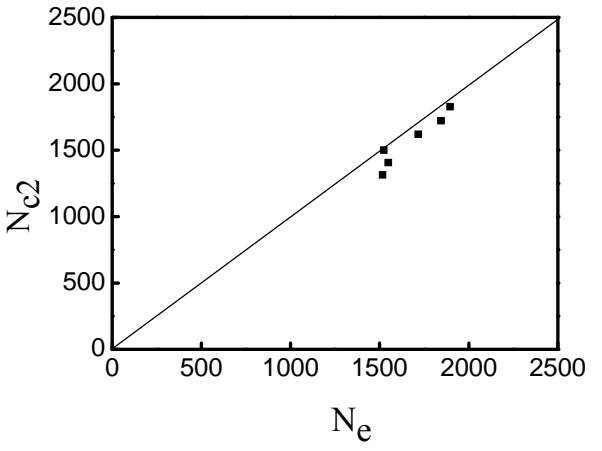

Figure 15. Comparison of Results of Simplified Method and Test Results 


\section{SIMPLIFIED METHOD OF BEARING CAPACITY}

Paper [1] proposed a simplified formula which is applied to predict the stability bearing capacity of CFST under bi-axial eccentric loading. The formula fits the condition that confinement coefficient $\xi=0.2 \sim 5$, yield strength of steel $f_{y}=200 \sim 700 \mathrm{MPa}$, cubic compressive strength of concrete $f_{c u}=30 \sim 120 \mathrm{MPa}$, steel ratio $\alpha=0.03 \sim 0.2$, slenderness ratio $\lambda=10 \sim 200$. Formula can be expressed as follows:

When $N / N_{u} \geq \varphi_{x}^{3} 2 \eta_{0}$

$\frac{N}{\varphi_{x y} N_{u}}+\frac{a}{d}\left[\left(\frac{M_{x}}{M_{u x}}\right)^{1.8}+\left(\frac{M_{y}}{M_{u y}}\right)^{1.8}\right]^{1 / 1.8} \leq 1$

When $N / N_{u}<2 \varphi_{x}^{3} \eta_{0}$

$-b \frac{N^{2}}{N_{u}^{2}}-c \frac{N}{N_{u}}+\frac{1}{d}\left[\left(\frac{M_{x}}{M_{u x}}\right)^{1.8}+\left(\frac{M_{y}}{M_{u y}}\right)^{1.8}\right]^{1 / 1.8} \leq 1$

Where $N_{u}$ is ultimate axial compressive strength of CFST; $\varphi_{x y}$ is stability coefficient of CFST under bi-axial eccentric loading; $M_{x}$ and $M_{y}$ are bending moment along the x-axis and y-axis respectively, which are given by $M_{x}=N e_{x}$ and $M_{y}=N e_{y}$; In this paper, the loading angle is $45^{\circ}$, and $e_{x}=e_{y}=50 \mathrm{~mm}$; $M_{u x}$ and $M_{u y}$ are flexural bearing capacity along the x-axis and y-axis respectively; Where a, b, c, d is calculating coefficient, $1 / \mathrm{d}$ is amplification factor of the bending moment considering the second-order effect. The detailed calculations of these parameters are given by paper [1].

The stability bearing capacity of test specimen was calculated with the simplified formula. Figures 15 shows calculation results $\left(N_{c 2}\right)$ and measured values $\left(N_{e}\right)$. The ratio of $N_{c 2} / N_{e}$ is listed in Table 2 whose average is 0.934 , standard deviation is 0.004 . It can be seen that the calculation results agree well with test data. It means that the simplified formula can be referred to calculate the bearing capacity of HCFST within the parameters of this test.

\section{PARAMETER ANALYSIS}

\section{$5.1 \quad$ Steel Ratio}

With a constant slenderness ratio and the steel ratio changing from $7 \%$ to $13 \%$, the ultimate bearing capacity of growth rates are $24.4 \%, 19.2 \%$ and $13.2 \%$ respectively. Table 2 shows that steel ratio is an important factor to influence ultimate bearing capacity. In addition, as slenderness ratio increases, the growth rate of the ultimate bearing capacity decreases.

\section{$5.2 \quad$ Slenderness Ratio}

Figure 16 shows the relationship of the load and slenderness ratios. When the steel ratio and eccentricity are constant, the bigger slenderness ratio is, the smaller the ultimate load bearing capacity is, because the stability coefficient $\varphi_{x y}$ reduces with the increasing of the slenderness ratio. In addition, Table 2 shows that with a constant slenderness ratio, the greater the steel ratio is, the bigger stability coefficient is. 
Figure 17 is the interaction curve of slenderness ratio and deflection. Steel ratio imposes little influence on the mid-span deflection when the slenderness ratio is 13.86 . With the increasing of slenderness ratio, the impact of steel ratio becomes obvious, because the bigger steel ratio and the greater stiffness of the specimen result in a small deflection of mid-span under the ultimate bearing capacity.

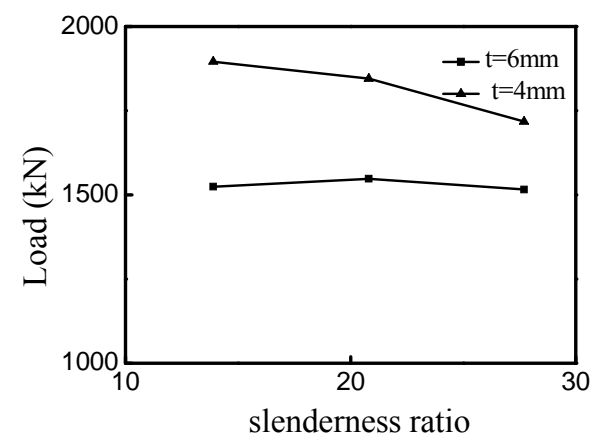

Figure 16. The Relationship between Load and Slenderness Ratios

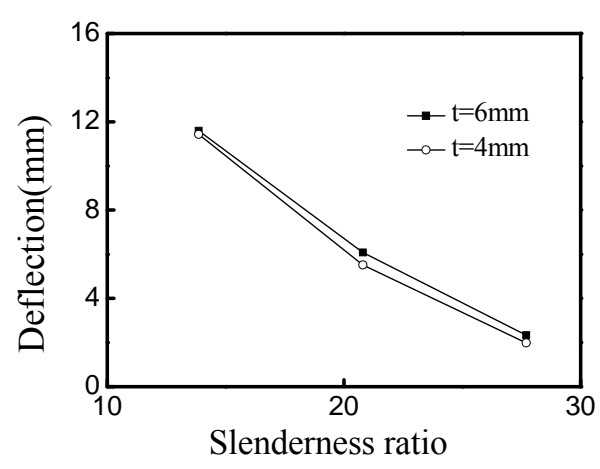

Figure 17 The Slenderness Ratio and Deflection Interaction Curves

\section{CONLUSIONS}

(1) The HCFST columns subjected to bi-axial eccentric loading failed to work because of instability, and showed a certain degree of ductility.

(2) The deflection curves of test fit the ideal half-sine-wave curves well. The strain curves of specimen are consistent with plane-section assumption.

(3) The ultimate bearing capacity of HCFST subjected to bi-axial eccentric loading resulted from analyzing with finite element software ABAQUS shows good agreements with the test data the numerical method is verified to be reliable in predicting the load versus deformation relationships.

(4) The simplified formula was used to calculate bearing capacity of the test specimens, and the calculation results agree well with test data. The simplified formula can be referred to calculate the bearing capacity of HCFST within the parameters of this test.

\section{ACKNOWLEDGEMENTS}

This project was supported by National Science Found of China (50678106), Shenyang Talent Development Fund (2009140403038) and Liaoning BaiQianWan Talents Program. 


\section{REFERENCES}

[1] Han, L.H., "Concrete-Filled Steel Tube Structure-Theory and Practice (Second Edition)", Science Press, 2008.

[2] Shosuke, M. and Keigo, T., "Design and Construction of Concrete-Filled Steel Tube Column System in Japan”, Earthquake Engineering and Engineering Seismology, 2003, Vol. 4, No. 1, pp. 51-73.

[3] Toshiaki, F, Akiyoshi, M, Isao, N. and Kenji, S., "Behavior of Eccentrically Loaded Concrete-Filled Steel Tubular Columns", Journal of Structural Engineering, 2004, Vol. 130, No. 2, pp. 203-212

[4] Han, L.H, Zbao, X.L. and Tao, Z., "Tests and Mechanics Model for Concrete-Filled and Beam-Columns", Steel and Composite Structures-An International Journal, 2001, Vol. 1, No. 1, pp. 51-74.

[5] Campione, G. and Scibilia, N., Beam-Column Behavior of Concrete Filled Steel Tubes", Steel and Composite Structures, 2002, Vol. 2, No. 4, pp. 259-276.

[6] Zegbicbe, J, Cbaoui K., "An Experimental Behaviour of Concrete-Filled Steel Tubular Columns", Journal of Constructional Steel Research, 2005, Vol. 61, No. 1, pp. 53-66.

[7] Mursi, M and Uy, B., "Behaviour and Design of Fabricated High Strength Steel Columns Subjected to Biaxial Bending, Part 1: Experiments", International Journal of Advanced Steel Construction, Hong Kong Institute of Steel Construction, 2006, Vol. 2, No. 4, pp. 286-315.

[8] Mursi, M. and Uy, B., "Behaviour and Design of Fabricated High Strength Steel Columns Subjected to Biaxial Bending, Part 2: Analysis and Design Codes", International Journal of Advanced Steel Construction, Hong Kong Institute of Steel Construction, 2006, Vol. 2, No. 4, pp. 316-54.

[9] Tokgoz, S. and Dundar, C., "Experimental Study on Steel Tubular Columns In-Filled with Plain and Steel Fiber Reinforced Concrete", Thin Walled Structure, 2010, doi:10.1016/j.tws.2010.01.009.

[10] Guo, L.H, Zhang, S.M. and Liu, J.P., "Experimental and Theoretical Analysis of Concrete-filled RHS Under Bi-axial Bending Moment”, Building Structure, 2008, Vol. 38, No. 3, pp. 22-28 (in Chinese).

[11] Bridge, R.Q., "Concrete Filled Steel Tubular Columns Report”, No. 8283, School of Civil Engineering, University, Sydney, Australia, 1976.

[12] Shakir-Khalil, H., "Further Tests on Concrete-Filled Rectangular Hollow-Section Columns", Structural Engineering, 1990, Vol. 68, No. 20, pp. 405-413.

[13] Al-Rodan, A. and Al-Tarawnab, S., "Fe Analysis of the Flexural Behavior of Rectangular Tubular Sections Filled with High-Strength Concrete", Emirates Journal for Engineering Research, 2003, Vol. 8, No. 1, pp. 71-77.

[14] Hu, H.T., Huang, C.S., Wu, M.H. and Wu, Y.M., "Nonlinear Analysis of Axially Loaded Concrete-Filled Tube Columns with Confinement Effect", Journal of Structural Engineering, 2003, Vol. 129, pp. 10, pp. 1322-1329.

[15] Hu, H.T. and Huang, C.S., "Finite Element Analysis of CFT Columns Subjected to An Anal Compressive Force and Bending Moment in Combination", Journal of Constructional Steel Research, 2005, Vol. 61, No. 12, pp. 1692-1712.

[16] Abdel-Rabman, N. and Sivakumaran, K.S., "Material Properties Models for Analysis of Cold-Formed Steel Members", Journal of Structural Engineering, 1997, Vol. 123, No. 9, pp. 1135-1143.

[17] Hillerborg, A., Modeer, M. and Petersson, P.E., “Analysis of Crack Formation and Crack Growth in Concrete by Means of Fracture Mechanics and Finite Elements, Cement and Concrete Research". 1976, Vol. 6, No. 6, pp. 773-782. 